\title{
AÇÕES CONJUNTAS E GANHOS COLETIVOS NO APL DE CALÇADOS FEMININOS DE JAÚ (SP)
}

Joint actions and collective gains in the application of female footwear in Jaú (SP)

Acciones conjuntas y ganancias colectivas en la aplicación del calzado feminino en Jaú (SP)

Received: august/2020

Accepted: september $/ 2020$

Available online: september/2020

Márcia Cristina Alves, UTFPR - Doutora em Engenharia de Produção, Universidade

Tecnológica Federal do Paraná, Brasil. E-mail: marciaalves@utfpr.edu.br

Fernando Celso de Campos, UNIMEP - Doutor em Engenharia Mecânica, Universidade Metodista de Piracicaba, Brasil. E-mail: fccanpos@unimep.br

Fernanda Cavicchioli Zola, UTFPR - Doutora em Engenharia de Produção, Universidade

Tecnológica Federal do Paraná, Brasil. E-mail: fzola@utfpr.edu.br

Fabiano Palhares Galão, UTFPR - Doutor em Administração, Universidade Tecnológica Federal do Paraná, Brasil, E-mail: fpgalao@gmail.com

Fábia Regina Gomes Ribeiro, UTFPR - Doutora em Engenharia Química, Universidade Tecnológica Federal do Paraná, Brasil, E-mail: fabiaribeiro@utfpr.edu.br

Marcelo Capre Dias, Doutor em Administração de Empresas, UTFPR - Universidade Tecnológica Federal do Paraná, Brasil, E-mail: capre@utfpr.edu.br 
Resumo: O objetivo desta pesquisa é constatar que as ações conjuntas realizadas entre os diversos atores do APL (Arranjo Produtivo Local) de Calçados Femininos de Jaú geram "ganhos coletivos" aos produtores e propiciam vantagens competitivas para a cadeia produtiva. O enfoque metodológico deste trabalho enquadra-se na pesquisa descritiva do tipo exploratória. Utilizou-se o método de estudo de caso para o desenvolvimento da pesquisa. Os resultados apontam que, embora constata-se baixa cooperação entre os produtores, as ações conjuntas deliberadas (economias externas ativas) entre os atores do APL geram ganhos coletivos e promovem vantagem competitiva na cadeia produtiva do aglomerado. O desenvolvimento local/regional atrai outras empresas (subsidiárias) para a proximidade do local, gerando empregos e renda.

Palavras-chave: Arranjo produtivo local, Indústria de calçados, Vantagem competitiva, Ganhos coletivos, Ações conjuntas.

\begin{abstract}
The objective of this research is to verify that the joint actions carried out between the various actors of the APL - Local Productive Arrangement of Women's Shoes in Jaú generate "collective gains" for producers and provide competitive advantages for the production chain. The methodological approach of this work fits into the exploratory descriptive research. The case study method was used for the development of the research. The results show that, although there is low cooperation between producers, deliberate joint actions (active external economies) between the APL actors generate collective gains and promote competitive advantage in the cluster's productive chain. Local/regional development attracts other companies (subsidiaries) close to the location, generating jobs and income.
\end{abstract}

Keywords: Local productive arrangement, Footwear industry, Competitive advantage, Collective gains, Joint actions.

Resumen: El objetivo de esta investigación es verificar que las acciones conjuntas realizadas entre los diversos actores del APL (Arreglo Productivo Local) para Zapatos de Mujer en Jaú generen "ganancias colectivas" para los productores y brinden ventajas competitivas para la cadena de producción. El enfoque metodológico de este trabajo se ajusta a la investigación exploratoria descriptiva. El método de estudio de caso se utilizó para el desarrollo de la investigación. Los resultados muestran que, aunque existe poca cooperación entre los productores, las acciones conjuntas deliberadas (economías externas activas) entre los actores de APL generan ganancias colectivas y promueven una ventaja competitiva en la cadena productiva del clúster. El desarrollo local/regional atrae a otras empresas (filiales) a la proximidad de la ubicación, generando empleos e ingresos.

Palabras clave: Arreglo productivo local, industria del calzado, ventaja competitiva, ganancias colectivas, acciones conjuntas.

\title{
INTRODUÇÃO
}


O tema sobre Arranjos Produtivos Locais (APL) está em pauta, no Brasil inúmeros trabalhos estão sendo publicados. A importância é atribuída para a consolidação desses arranjos como fator de sobrevivência das pequenas e médias empresas, para a geração de renda e para o desenvolvimento local e regional.

Segundo Cassiolato e Lastre (2003) o reconhecimento e o aproveitamento das sinergias coletivas geradas pela participação das empresas em Arranjos Produtivos Locais fortalecem as chances de sobrevivência e crescimento das MPME (Micro, Pequenas e Médias Empresas) e constitui importante fonte geradora de vantagens competitivas duradouras.

O crescente interesse pela investigação dos arranjos produtivos locais trouxe algumas dificuldades devido à extensa variedade de termos que são utilizados para fazer referência a esses arranjos locais. Porém, o pressuposto básico é que “as aglomerações de empresas’ em uma mesma região são capazes de produzir "vantagem competitiva" aos produtores que não estariam disponíveis se estes estiverem atuando isoladamente.

A concentração geográfica é capaz de proporcionar economias externas à firma que são apropriadas pelo conjunto dos produtores. Essas externalidades são o que Marshall (1982), em sua análise dos "distritos industriais" na Inglaterra no final do século XIX, chamou de retornos crescentes de escala e que são externos à firma, mas internos ao sistema local.

Como exemplos mais clássicos deste tipo de estudo, encontram-se os Distritos Industriais na chamada Terceira Itália, o Vale do Silício na Califórnia, ou a região de Baden-Wurttemberg na Alemanha, entre outros (VARGAS, 2003).

Verificou-se também o estudo dos "clusters industriais", mileux innovaters, incubadoras de empresas, e os APL. A revisão da literatura contribuiu para a compreensão teórica do tema proposto neste artigo, e o caso empírico do APL de Calçados Femininos de 
Jaú/SP ilustra os projetos e as ações conjuntas que estão sendo realizadas no arranjo através do Sindicalçados, com o apoio do SEBRAE e das diversas instituições privadas e públicas (federal, estadual e municipal).

O APL de calçados de Jaú apresenta uma característica diversificada e única em relação aos outros APL de calçados brasileiros devido à flexibilidade da produção (mudança constante dos modelos de calçados), da especificidade da fabricação artesanal e da qualificação da mão-de-obra especializada para os calçados femininos.

Observa-se que os APL passaram a ser pauta da estratégia do governo brasileiro, que está apoiando as empresas de pequeno e médio porte em todo território nacional (Lei $\mathrm{n}^{\mathrm{o}}$ 10.973, de 01/12/2004) - através de incentivos à inovação e a pesquisa científica e tecnológica no ambiente produtivo. O Ministério da Ciência e Tecnologia tem procurado informar e disponibilizar o programa "Fóruns Regionais, Inclusão Social e Redes de Cooperação" com o objetivo governamental de criação de políticas de apoio para APL.

O SEBRAE tem a política de apoiar e incentivar a criação de arranjos produtivos locais verifica-se que a maioria dos APL de diversos segmentos tem o SEBRAE como membro integrante de sua governança, assim como as instituições de ensino local/regional tem um papel fundamental no desenvolvimento e na inovação do arranjo.

Suzigan (2005, p. 87) afirma que a ação conjunta de empresas e outros agentes localizados favorecem a geração de inovações, levando à criação de diferentes tipos de instituições de ensino, pesquisa e prestação de serviços que melhoram as capacitações técnicas, tecnológicas e inovativa de cada empresa e conseqüentemente aumentam a capacidade de inovação do sistema. Por tanto, ações conjuntas geram ganhos coletivos para todos os atores presentes no arranjo local, estendendo-se muitas vezes para a região e para o país. 
A seguir apresenta-se a metodologia da pesquisa; a caracterização do APL de Calçados Femininos de Jaú/SP; as principais características das indústrias que fizeram parte desta pesquisa; os programas e os projetos de ações conjuntas que estão sendo realizados pelos diversos atores do APL; a análise dos resultados da pesquisa empírica referente ao objetivo geral, objetivos específicos, hipótese principal e hipóteses secundárias da pesquisa de campo; e as considerações finais desta pesquisa. A revisão teórica sobre o tema da pesquisa será descrita e apontada durante o decorrer deste trabalho tendo o objetivo de corroborar com os resultados empíricos da pesquisa.

\section{Metodologia Adotada na Pesquisa}

O enfoque metodológico deste trabalho enquadra-se na pesquisa descritiva (Chizzotti, 1991; Gil, 1987; Richardson, 1999; Lakatos e Marconi, 1995) com o objetivo de estudar as características de organizações e observar um determinado grupo. A pesquisa descritiva observa, registra, analisa e correlaciona fatos ou fenômenos (variáveis) sem manipulá-los.

Os estudos descritivos contemplam a formulação clara do problema e da hipótese como tentativa de solução (CERVO e BERVIAN: 2002; p. 66-67), esses estudos também são chamados de hipotéticos - dedutivos. Com relação ao objetivo, a pesquisa pode ser considerada exploratória, pois os levantamentos e entrevistas realizadas no setor calçadista proporcionam maior familiaridade com o problema pesquisado. A abordagem da pesquisa é qualitativa com utilização de estatística descritiva.

O método adotado é o estudo de caso (YIN 2001), o estudo de caso é uma pesquisa sobre um grupo ou comunidade que seja representativo do seu universo (Cervo e Bervian, 2002). O estudo de caso é uma metodologia apropriada para determinados tipos de problemas, 
como aqueles em que a pesquisa e teoria estão em estágio inicial de formação, ou aqueles baseados na prática, quando a experiência dos atores é importante e o contexto de ação é crítico.

A escolha da amostra situou-se na categoria de não-probabilística e foi selecionada de forma intencional e por conveniência ${ }^{1}$. O questionário foi elaborado com perguntas abertas e fechadas para atender o objetivo geral, os objetivos específicos e para a confirmação ou não-confirmação das hipóteses formuladas nesta pesquisa.

Devido à dificuldade de avaliar os fatores de importância adotou-se como métrica de comparação de mensuração do grau de importância, a média ponderada de pesos atribuídos a cada grau de importância: Baixo: (1), Médio (2) e Alto (3) pelo respectivo número de respostas observado. A análise comparativa entre os fatores de importância foi realizada a partir da construção de um ranking dos valores de média ponderada calculados.

\section{Características do Arranjo de Calçados Femininos de Jaú/SP}

O APL de Jaú está localizado na Região Centro Oeste do Estado de São Paulo, distando $300 \mathrm{Km}$ da Capital e é especializado na produção de calçados femininos de couro. O APL Calçadista de Jaú compreende as Cidades de Jaú, Barra Bonita, Dois Córregos, Mineiros do Tietê, Bocaina e Bariri. O "Pólo Calçadista de Jaú (SP)" começou a surgir na década de 1950, o produto produzido nesta primeira indústria era o calçado masculino por ser mais fácil de confeccionar e também porque a modelagem desse tipo de calçado não muda

\footnotetext{
${ }^{1}$ Foram selecionadas vinte e três (23) indústrias de calçados de couro e duas (2) indústrias de calçados sintéticos. Das vinte e três (23) indústrias selecionadas, quinze (15) receberam para as entrevistas e responderam os questionários (indústrias de pequeno e médio porte). Cinco (5) indústrias não receberam para a entrevista, pediram para deixar o questionário e retirá-los nas próximas semanas, porém não responderam no prazo estipulado pela pesquisadora e três (3) disseram que não respondem questionários (empresas consideradas de grande porte).
} 
constantemente. Nesta época não existia mão-de-obra especializada dentro do município. A mão-de-obra escassa proporcionava uma oferta de melhores salários para alguns operários e provocava uma disputa entre os empresários pelos melhores sapateiros ${ }^{2}$. Desta forma, vários empresários faziam propostas e retiravam funcionários de outras fábricas para trabalharem nas suas próprias.

Os empresários ensinavam moços e moças a trabalharem com o calçado, pois não havia mão-de-obra qualificada e a única forma de se aprender o ofício era "aprender fazendo". Gradativamente Jaú foi se tornando a capital do calçado feminino do Estado de São Paulo, título este que surgiu por acaso ${ }^{3}$. A estrutura industrial que foi criada para a produção de calçados passou a ser a meta para todos os membros da família através de uma estrutura organizacional totalmente familiar. A produção do calçado é simples quando comparada a outros setores, e o custo para se implantar uma "fabriqueta" é muito pequeno.

Até a década de 70 o "Pólo de Calçados de Jaú" contavam com apenas 37 indústrias de calçados. Á partir da década de 80 iniciou-se um "poll”, ou seja, a partir deste período as empresas fornecedoras de insumos começaram a instalar-se na cidade e criou-se uma cadeia produtiva mais densa, muitas empresas instalaram escritórios de representações, lojas e depósitos de componentes para calçados. Esta mudança contribuiu para a facilidade de compra e aumento de opções na qualidade e no preço.

As características das indústrias do APL de Jaú são predominantemente de pequenas empresas. O processo produtivo das pequenas, médias e grandes empresas é diferente. As grandes e as médias empresas produzem em série (produção é dividida em etapas), enquanto que nas pequenas empresas a produção é tipicamente artesanal, com o uso de poucas

\footnotetext{
${ }^{2}$ Sapateiros: operários que trabalham nas fábricas de calçado, no setor produtivo.

${ }^{3}$ Como os pioneiros produziam calçados femininos, os funcionários que saíam destas fábricas para montarem a sua própria empresa entravam também no ramo feminino, por causalidade de especialização de mão-de-obra no município, tanto os operários como os empresários só dominavam as técnicas da fabricação de calçados femininos.
}

RBPPD/BRJPD| Vol. 2 | n. 3 |p. 294-333, 2020. 
máquinas. A busca de maior qualidade do produto desperta o interesse dos empresários em incorporar máquinas modernas, mas a sazonalidade ${ }^{4}$ das vendas do setor e a escassez de capital de giro, juntamente com a ausência de uma linha de crédito dificultam o processo de modernização das indústrias instaladas na região. Somente as empresas maiores conseguem adquirir máquinas mais modernas e vendem as antigas para os pequenos produtores.

Existe uma diversificação da estrutura de mercado entre os calçados masculinos e femininos. Os calçados masculinos por manterem uma linha básica em termos de design, não exigem das empresas uma "flexibilidade" tão grande quanto os calçados femininos, para os quais a influência da moda é muito mais significativa.

Segundo Contador Júnior (2004), em geral, as barreiras não-técnicas são as mais importantes nesse mercado. Envolve principalmente, a diferenciação de produto por meio de design sofisticado, fixação de marcas e estratégias de marketing agressivas. Em relação à produção do calçado feminino são verificadas algumas facilidades produtivas e comerciais em relação ao calçado masculino, tais como: i) a moda feminina muda rapidamente para acompanhar a moda mundial e exige "flexibilidade" das empresas; ii) o mercado de calçados femininos é maior que o masculino; iii) o consumo dos calçados femininos é maior, cada consumidora compra em média 5 a 7 pares de calçados por ano; iv) o calçado feminino exige materiais menos resistentes e mais fáceis de trabalhar, enquanto que o calçado masculino deve ser mais robusto e resistente.

A cadeia produtiva do calçado de couro, matéria prima principal dos calçados possui uma complexidade e apresenta entraves que ocorrem desde a produção do couro até o seu curtimento. A cadeia produtiva é composta por várias empresas, apresenta enorme

\footnotetext{
${ }^{4}$ Sazonalidade: Períodos de produção na indústria do calçado. Período considerado, em termos de produção e venda 'bom': meses de março, abril, maio, agosto, setembro, outubro, novembro e dezembro. Período considerado 'médio': fevereiro e junho. Período considerado 'ruim': janeiro e julho.
} 
heterogeneidade em suas estruturas e em seus processos produtivos, e precisa de atualização tecnológica para fazer face à concorrência internacional.

O APL de Jaú busca a interligação de fornecedores e produtores, criando uma cadeia produtiva que depende diretamente da participação de outros Estados e municípios do Estado/SP para viabilizar a produção de calçado e gerar diferenças no produto final. No APL de Jaú, 75\% da produção são de calçados de couro. Das matérias-primas (couro) utilizadas na produção do calçado feminino de Jaú, $60 \%$ são provenientes de outras localidades ${ }^{5}$. Existe uma rede de subcontratadas e a presença de escritórios de representação de matéria-prima que facilita o fornecimento de matéria-prima e componentes. Devido a capacidade de produção do arranjo (130.000 pares por dia) grandes produtores de matérias-primas não instalam suas fábricas no Município.

O calçado feminino deve ter diversidade criativa, acompanhar a moda, ter preços baixos para os compradores, pois grande parte das pequenas e médias empresas competem pelo mercado popular. Esses fatores são importantes para o desafio da modernização das empresas, solidificação e crescimento sustentável das indústrias do APL de calçados femininos de Jaú.

Outra característica marcante do APL de Jaú é a qualificação da mão-de-obra, uma parte dos sapateiros possui baixa escolaridade, o aprendizado ocorre através de treinamento repetitivo da atividade dentro da indústria. Embora a mão-de-obra de Jaú seja altamente especializada (produção artesanal) terá que passar por um processo de requalificação, pois não

\footnotetext{
${ }^{5}$ Os principais fornecedores de matéria-prima, máquinas e equipamentos estão localizados no cluster de Franca (SP) e no cluster do Rio Grande do Sul (Vale do Sinos). Pesquisas realizadas por diversos autores apontam grande quantidade de "indústrias correlatas e de apoio" instaladas nestes arranjos e uma configuração completa de fornecedores em sua cadeia produtiva.
}

RBPPD/BRJPD| Vol. 2 | n. 3 |p. 294-333, 2020. 
está preparada para utilizar novas tecnologias, como programas computacionais e até mesmo novas máquinas capazes de agilizar o processo produtivo, estando muito distante ainda da introdução da robótica na produção como é o caso do distrito industrial da Terceira Itália. (OLIVEIRA, 1999)

Há facilidade de adaptação da mão-de-obra feminina na confecção de calçados, porém foi a que mais deixou a fábrica, a maioria passou a trabalhar em bancas de pesponto (empresas informais instaladas nos fundos das residências).

Oliveira, (1999) comenta que a mão-de-obra em Jaú é uma das melhores do país na produção de calçado, porém é também uma das mais caras, quando comparadas com outros pólos calçadistas. A média de salários em Jaú (três salários mínimos) é maior que a média salarial paga pelos Pólos de Franca (SP) e do Vale dos Sinos (RS).

A discussão sobre a "terminologia" de que Jaú é um "Pólo" ou um "APL" teve início em 2001, com um "surto de exportação", o qual não deu certo. A partir deste momento começou-se a discussão e algumas questões surgiram: Por que exportar? Qual é a estrutura das indústrias de Jaú? É Familiar? O que precisa ser mudado? As indagações deram início à criação de uma estrutura de governança com apoio do Sindicalçados. Neste mesmo ano os empresários se juntaram para fazer a coleta do lixo de suas indústrias, iniciando a primeira ação conjunta do APL. Muitos empresários comentam: "Os empresários de Jaú uniram-se por causa do lixo".

Em 2003 o Sebrae visando apoiar e fomentar o desenvolvimento regional de MPMEs identificou o "Pólo calçadista de Jaú" como prioridade de investimento nos projetos e programas e consolidou o Pólo de Jaú como um APL.

Os autores Suzigan, Furtado et al., (2005, p. 25-48) fazem referência ao indicador de localização ou de especialização, o qual tem sido amplamente utilizado em estudos de 
economia e desenvolvimento regional (primeira contribuição dada por Isard em 1960). A verificação de um Quociente de Localização (QL) elevado em determinada indústria numa região (ou município) indica a especialização da estrutura de produção local naquela indústria. Quanto maior o QL de determinada atividade, maior será o grau de especialização do município analisado naquela atividade e verificada na média do país. Deste modo o município de Jaú apresenta QL=17,6, que demonstra um alto grau de especialização no segmento de calçados.

Segundo Campos (2003), as diversas variáveis levadas em conta para a tipificação de um APL podem ser apontadas como: i) o grau de cooperação entre os produtores; ii) a estrutura interna do aglomerado; iii) as características das empresas; iv) o papel do setor público; v) o principal mercado atendido; vi) a qualidade do produto; vii) a importância para a economia local ou regional; viii) o grau de tecnologia do produto ou processo; ix) a identidade sócio-cultural; x) a qualificação da mão-de-obra; xi) a qualificação do quadro administrativo; xii) a presença de instituições de pesquisa; xiii) o nível de informalidade das empresas, segundo o autor "não existe uma única tipologia possível”.

Em 2006, o APL de Calçados Femininos de Jaú possuía 655 estabelecimentos na cadeia produtiva do couro (empresas prestadoras de serviço, fabricantes de componentes, curtumes, artefatos de couro, atacadistas e representantes de componentes), englobando 250 fábricas de calçados. Possuía três (3) shoppings de calçados, com 200 lojas de calçados (vendas no atacado e varejo). O arranjo produtivo de calçados gera 16.130 empregos diretos e indiretos. Possui aproximadamente 400 empresas de bancas e pespontos informais (estimativa que não possui estatística para ser confirmado - é um indicativo informal).

Segundo o Sindicalçados, o APL de Jaú produz atualmente entre 130 mil a 150 mil pares de calçados femininos por dia, possui capacidade instalada para produzir mais $30 \%$. Em 
2010 o APL exportou US\$ 1.016.255,00, tendo como destino a Europa, Arábia Saudita e América do Sul.

\section{Características das Indústrias do Arranjo de Calçados Femininos/Jaú}

Através da pesquisa empírica identificou-se as principais características das indústrias de calçados femininos de Jaú:

Quadro 1- Características das indústrias de calçados femininos de Jaú

\begin{tabular}{|l|l|}
\hline $\begin{array}{l}\text { Caracterização das } \\
\text { Indústrias arranjo de calçados } \\
\text { femininos de Jaú }\end{array}$ & $\begin{array}{l}\text { Característica dos arranjos "informais": micro e pequenas } \\
\text { empresas, com a presença de baixo nível tecnológico e com } \\
\text { poucas ou inexistentes barreiras à entrada de novas empresas. } \\
\text { Existem aproximadamente 400 empresas informais (bancas de } \\
\text { pesponto). As empresas possuem "gestão familiar". A maioria } \\
\text { das empresas tem dois sócios. É muito comum toda a família } \\
\text { trabalhar na empresa. }\end{array}$ \\
\hline Porte das Indústrias & $\begin{array}{l}\text { Médias empresas (40\%) } \\
\text { Pequenas empresas (60\%) }\end{array}$ \\
\hline $\begin{array}{l}\text { Divisão das tarefas na } \\
\text { empresa }\end{array}$ & $\begin{array}{l}\text { Geralmente os homens são responsáveis pela criação dos } \\
\text { modelos, pois conhecem o processo produtivo, matéria-prima, } \\
\text { máquinas e equipamentos. Algumas mulheres são responsáveis } \\
\text { pela área financeira e administrativa, porém a maioria das } \\
\text { "esposas" dos empresários administram as lojas do shopping de } \\
\text { calçados de Jaú. }\end{array}$ \\
\hline $\begin{array}{l}\text { N de funcionários } \\
\text { funcionários de funcionários nas empresas varia de 03 a 70 }\end{array}$ \\
\hline $\begin{array}{l}\text { Etapas do Processo } \\
\text { Produtivo na empresa e } \\
\text { Terceirizado }\end{array}$ & $\begin{array}{l}\text { Na própria empresa (58\%) } \\
\text { Nas bancas de pesponto (maioria informal) (42\%) }\end{array}$ \\
\hline Nível de Escolaridade & A maioria dos funcionários possui ensino fundamental \\
\hline $\begin{array}{l}\text { Qualificação da } \\
\text { mão-de-obra }\end{array}$ & $\begin{array}{l}\text { A maioria dos empresários pretende intensificar a qualificação } \\
\text { dos funcionários (93\%) }\end{array}$ \\
\hline $\begin{array}{l}\text { Treinamento dos } \\
\text { funcionários }\end{array}$ & $\begin{array}{l}\text { A maioria é treinada na própria empresa ou instituições } \\
\text { localizadas na cidade }\end{array}$ \\
\hline $\begin{array}{l}\text { Produtos fabricados pelas } \\
\text { indústrias do APL de Jaú }\end{array}$ & $\begin{array}{l}\text { Fabricam calçados de couro (74\%) } \\
\text { Fabricam calçados sintéticos (13\%) } \\
\text { Fabricam calçados de couro e bolsas de couro (13\%) }\end{array}$ \\
\hline $\begin{array}{l}\text { Destino da produção dos } \\
\text { calçados das "Médias } \\
\text { Empresas" }\end{array}$ & $\begin{array}{l}\text { São Paulo/ Capital (46\%) } \\
\text { Outros Estados: Paraná, Minas Gerais, Mato Grosso do Sul, Rio } \\
\text { Grande do Sul, Santa Catarina, Rio de Janeiro, Bahia (35\%); } \\
\text { interior do Estado de São Paulo (17\%) }\end{array}$ \\
\hline
\end{tabular}




\begin{tabular}{|l|l|}
\hline & $\begin{array}{l}\text { Exterior: Mercosul, América Central, Emirados Árabes, Kuwati, } \\
\text { Ásia, EUA, Líbano e Israel (2\%) }\end{array}$ \\
\hline $\begin{array}{l}\text { Destino da produção de } \\
\text { calçados das "Pequenas } \\
\text { Empresas" }\end{array}$ & $\begin{array}{l}\text { São Paulo/Capital (38\%) } \\
\text { São Paulo/Interior (35\%) } \\
\text { Outros Estados: Minas Gerais, Rio de Janeiro, Paraná (27\%) }\end{array}$ \\
\hline $\begin{array}{l}\text { Vantagens e desvantagens } \\
\text { em utilizar fornecedores do } \\
\text { local, da região e de outros } \\
\text { estados são os mesmos }\end{array}$ & $\begin{array}{l}\text { As prioridades apontadas foram: Rapidez na entrega; Custo de } \\
\text { transporte; Assistência técnica oferecida; e Qualidade }\end{array}$ \\
\hline $\begin{array}{l}\text { Principais fornecedores } \\
\text { presentes no arranjo local }\end{array}$ & $\begin{array}{l}\text { Matéria-prima; Enfeites, Saltos, Palmilhas, Material para } \\
\text { Couraça, Material para Cabedal, Materiais para Contraforte, } \\
\text { Solados, Caixas Individuais, Caixas Coletivas }\end{array}$ \\
\hline $\begin{array}{l}\text { Fornecedores localizados } \\
\text { na Região (Franca) e no } \\
\text { Rio Grande do Sul }\end{array}$ & $\begin{array}{l}\text { Máquinas e Equipamentos, Matérias-primas, Enfeites, Cola, } \\
\text { Fivelas, Solados. }\end{array}$ \\
\hline
\end{tabular}

Fonte: elaboração dos autores (2016)

Analisando as principais características das indústrias calçadista de Jaú constatou-se que a maioria das empresas é de pequeno porte, não possuem política de treinamento e de recrutamento dos funcionários e não exigem escolaridade mínima para a contratação. A maioria das empresas não remuneram os funcionários pela produtividade (o salário é pago pelo piso da classe) acarretando "um certo" desinteresse dos empregados em melhorar a sua qualificação, pois não vêem oportunidades de ganhar mais ou de mudar de função por terem adquirido novas competências. Os calçados femininos possuem uma "especificidade única" que acompanham a moda das estações e a flexibilidade da mão-de-obra é intensa.

A maioria dos funcionários possui baixo grau de escolaridade, uma das principais falhas das empresas é a falta de treinamento. A eficiência da mão-de-obra em relação à produtividade e qualidade é adquirida com a prática na própria empresa. Segundo depoimento de um empresário, "Os funcionários levam de um a três meses para aprenderem à função (dependendo da função que irá assumir) e são acompanhados pelos funcionários mais experientes".

Uma das "economias externas" verificadas na literatura é a concentração de um contingente de mão-de-obra especializada nos arranjos produtivos locais de empresas do 
mesmo segmento. Marshall (1982), afirmava que a concentração da mão-de-obra especializada e o treinamento representam custos reduzidos para as empresas que se apropriam do processo de aprendizado que são endógenos a elas, porém exógenos ao conjunto local de produtores. Porém no APL de Jaú falta mão-de-obra qualificada, as empresas absorvem todo o contingente existente no município.

Observou-se que existe baixa entrave de novas empresas no arranjo, alguns funcionários "saem" das empresas e montam suas próprias empresas. Segundo depoimento de um empresário: “Eu tinha um funcionário que resolveu montar a sua empresa e eu emprestei uma máquina que não estava usando para ele iniciar a sua produção”. Alguns funcionários montam empresas para fornecer partes (bancas de pesponto) do produto para empresas que já estão atuando a mais tempo no mercado.

Outra característica verificada no APL de Jaú é que os empresários montam fábricas para os seus filhos. "Eu montei uma empresa para minha filha, ela fabrica bolsas de couro, eu auxílio ela na parte financeira e ela cria os modelos das bolsas”. Outro empresário comenta: "Vou montar uma fábrica de calçados para o meu filho, quero que ele entre no mercado, mas que ele tenha a sua própria fábrica”. Esses empresários já estão no segmento de calçados a mais de 20 anos, possuem muita experiência e fabricam calçados com maior valor agregado (calçados para festa).

A maior parte das empresas do arranjo fabrica calçado de couro (preferência das clientes/mulheres). $\mathrm{O}$ designer acompanha a moda (faz sucesso junto às consumidoras finais) e é primordial por serem mais refinados e possuírem maior valor agregado (aparência, conforto, estilo, forro, enfeites, cores, formato, saltos, fivelas, etc), do que os calçados sintéticos (plástico/polouretano-PU) que possuírem poucos acessórios. 
Os calçados de couro são produzidos quase que "manualmente" (semi-artesanais), equipados com ferramentas e máquinas simples e com fortes barreiras à automação. Pode-se dizer que a produção possui características da produção "fordista" (presença de esteiras de produção). O maior problema que impede a automação da produção de calçados de couro é a principal matéria-prima “o couro" devido a irregularidades (defeitos, espessura não-uniforme, elasticidade, sentido das fibras, baixa qualidade, marcas de arame farpado e espinhos, ectoparasitoses, marca a fogo dos animais, transporte inadequado, etc). A maior parte destes defeitos tem origem no campo, impedindo a produção automatizada.

De acordo com o SEBRAE (2003), o baixo índice de exportação dos calçados do APL de Jaú reside principalmente na: i) inexistência de política industrial e de comércio exterior; ii) queda nas alíquotas de importação; iii) excessiva burocracia nas importações; iv) elevados custos para financiamento de investimentos; v) agressividade dos concorrentes asiáticos; vi) desigualdades tarifárias que privilegiam a exportação de matérias-primas para concorrentes produtores de manufaturados (wet blue: couro cru) e que não sofre qualquer gravame; e vii) falsa imagem de setor poluidor e de trabalho em condições inadequadas (noticiário de que o setor é poluidor, apresenta condições de escravidão e de emprego de mão-de-obra infantil).

Outro item verificado no APL de Jaú é o prazo de entrega das matérias-primas. As pequenas empresas fabricam pequenos lotes de acordo com os pedidos dos clientes. A empresa só faz o pedido da matéria-prima após fechamento das vendas. Os empresários reclamam: "Pelo fato dos meus pedidos serem pequenos tenho dificuldade com a entrega do couro, pois os fornecedores atendem em primeiro lugar os produtores que produzem grande quantidade e acabam atrasando os meus pedidos, os meus clientes reclamam muito do meu atraso na entrega dos calçados. A maioria dos clientes diz que as indústrias de Jaú não cumprem os prazos de entrega dos calçados”. 
Identificou-se que a relação com os fornecedores é razoável, as empresas testam os fornecedores e se forem aprovados adquirem confiança em relação ao prazo de entrega e qualidade, mantendo relações duradouras com eles. Os empresários comentam: “Os prazos de financiamentos deixam a desejar, as pequenas empresas não têm poder de negociação devido ao pequeno volume comprado”.

A literatura aponta que a presença de "indústrias correlatas e de apoio" (fornecedores e serviços especializados) é uma das "economias externas positivas mais importantes". A concentração geográfica e setorial das empresas atrai novas empresas para o local e estabelece relações duradouras entre os fornecedores. Verificou-se que nem todas as indústrias fornecedoras (matéria-prima, máquinas e equipamentos) fazem parte da cadeia produtiva do APL de Jaú, mas muitas empresas fornecedoras possuem escritórios de representações e depósitos de componentes instalados na cidade. As ações conjuntas entre os produtores como, por exemplo, “a compra conjunta de matérias-primas" não é uma prática comum no arranjo: "Nós tentamos fazer um grupo com alguns produtores de calçados para comprar cola em conjunto de um fornecedor do Rio Grande do Sul para diminuir o custo. Porém veio outro fornecedor e ofereceu um preço menor para alguns dos produtores do grupo e eles acabaram saindo do grupo e compraram a cola do fornecedor por um preço mais baixo”.

A ação conjunta deliberada entre os produtores do APL de Jaú para compra conjunta apresentou-se baixa, segundo Putnam (1996), a cooperação e a confiança representam o sucesso e a eficiência dos arranjos produtivos locais. $\mathrm{O}$ capital social diz respeito às características da organização social e está ligado através da confiança, das normas, das relações sociais existentes na cadeia produtiva. A confiança e a cooperação são derivadas de ambientes históricos e de acúmulo de capital social, os quais são adquiridos ao longo do tempo. 


\section{Ações Conjuntas e Ganhos Coletivos no APL de calçados Jaú/SP}

Desde 2003, o APL de calçados de Jaú tem planejado ações organizadas por um sistema de gestão orientado para resultados desenvolvido pelo SEBRAE e com o apoio do Sindicalçados para alavancar o desenvolvimento e a competitividade do arranjo.

O objetivo das ações é conquistar e manter novos mercados, aprimorar a gestão produtiva, aumentar e qualificar a mão-de-obra produtiva, melhorar e desenvolver fornecedores, aumentar as exportações, melhorar e fortalecer o design como diferencial competitivo, melhorar a gestão ambiental, reduzir os déficits comerciais da indústria de componentes para couro e calçados, garantir o aumento da demanda por máquinas, equipamentos e componentes por meio de upgrading tecnológico, e fortalecer a gestão do APL de calçados de Jaú.

O investimento para as ações e projetos é de aproximadamente 9 milhões de reais. Contribuíram para este investimento: SENAI: 1 milhão e 40 mil reais. Prefeitura Municipal de Jaú: 1 milhão e 690 mil reais. SINDICALÇADOS: 497 mil reais. Empresários de Jaú: 2 milhões e 566 mil reais (50 empresários). FATEC: 760 mil reais. IPT-Instituto de Pesquisa e Tecnologia (USP/SP): 306 mil reais. SEBRAE: 2 milhões e 265 mil reais. FINEP: 400 mil reais (para ações ambientais).

A seguir apresenta-se de forma resumida o estudo da atividade empresarial, os programas, os principais projetos e as ações conjuntas do APL de calçados femininos de Jaú com o apoio de atores públicos e privados (local, regional, estadual e federal).

\section{Estudo da Atividade Empresarial do Arranjo}

RBPPD/BRJPD| Vol. 2 | n. 3 |p. 294-333, 2020. 
Planejamento Estratégico, busca levantar e identificar ameaças e oportunidades do setor. O Programa SIGIOR descreve as metas, os objetivos, atividades a serem desenvolvidas, os recursos alocados. A metodologia usada é do SEBRAE.

\section{Programa de Desenvolvimento Sustentável APL Calçadista de Jaú}

O programa é participativo e integra toda a comunidade através de atividades coordenadas e conjuntas de diversas ações que propiciem a evolução do APL de forma sustentável. É importante salientar que o APL de calçadista de Jaú é o primeiro dentro deste segmento a implantar ações estratégicas voltada para a gestão ambiental, nenhum outro APL, Pólo ou cluster do Brasil possui este projeto. Principais parceiros do projeto: Secretaria Municipal de Desenvolvimento Econômico, o SEBRAE/Bauru, FIESP, CIESP, SENAI, SESI, SENAC, FATEC, UFSCar, IPT (Instituto de Pesquisas Tecnológicas), Sindicato dos Trabalhadores nas Indústrias de Calçados, Prefeitura Municipal, Ministério do Desenvolvimento da Indústria e Comércio e aproximadamente 50 empresas.

\section{Programa de Gestão de Resíduo ${ }^{6}$}

Produzir os chamados "compósitos de materiais polimétricos" que possam ser utilizados como matéria prima no setor de calçados. Coleta e processamento dos resíduos, criação de novos produtos, patentes do material desenvolvido, redução dos resíduos sólidos produzidos no APL de Jaú.

\footnotetext{
${ }^{6}$ A iniciativa chamada de "Jaú Recicla" tem como objetivo aproveitar rebarbas de chapas de solados, injetados e cepa (PU, SBR, NBR, EVA), raspas de couro e PU sintético para produzir ao menos dois materiais sintéticos a serem usados na produção de calçados. Um deles para produzir chapas espumadas para solados e o outro para criar saltos moldados por injeção.
}

RBPPD/BRJPD| Vol. 2 | n. 3 |p. 294-333, 2020. 


\section{Projetos e Ações Conjuntas do APL de Calçados Femininos de Jaú}

- Identificação e Prospecção de Novos Mercados: trazer compradores da América Latina para visitar as indústrias do APL.

- Participação das Empresas nas Feiras do Setor Calçadista: visita e montagem de estande de empresas nas principais feiras do setor.

- Central de Negócios: "Rodada Internacional de Negócios" tem o objetivo de aproximar pequenas e médias empresas com os grandes compradores para aumentar as chances de fechar as vendas. (Ocorre nas feiras de calçados).

- Programa de Qualidade Total: cursos direcionados aos empresários sobre qualidade total (SEBRAE).

- Programas de Gestão em Design: cursos e palestras de design como ferramenta estratégica de competitividade (Senai, Senac, Assintecal e São Paulo design).

- Cursos para Tecnólogos em Calçados: curso Superior de Tecnologia da Gestão de Produção de Calçados - FATEC, com respaldo da UNESP/Bauru.

- Pós-Graduação em Negócios/Gestão em Calçados: curso de MBA, para empresários e gerentes. Parceria com Universidade do Vale do Rio Sinos (RGS).

- Fórum Industrial da Cadeia Produtiva de Jaú e Região: evento realizado pela Assembléia Legislativa Paulista em parceria com o CIESP. Discutir as vantagens competitivas do APL, fortalecimento do setor e o crescimento das empresas locais.

- Programa de Capacitação de Empresários: estimular a mudança de atitude dos empresários para enfrentar os desafios de mercado. (SEBRAE e Sindicalçados).

- Programa de Consultoria Disponível no APL de Jaú: consultoria individual aos empresários em todas as áreas da empresa. (SEBRAE e Sindicalçados). 
- Programa IAPC e Indicadores Setoriais: quantificação da produção mensal de calçados com 80 empresas de médio e grande porte do Brasil e que respondem por $30 \%$ da produção calçadista. (UFRG e Assintecal).

- Fortalecimento da Governança: rede de governança estratégia de desenvolvimento das ações de promoção e criação de cenário futuro do APL.

- Núcleo de Desenvolvimento Empresarial: Incubadora de MPMEs da cadeia produtiva de calçados. Apoio Prefeitura Municipal, FIESP, SENAI e SEBRAE.

- Crédito aos Empresários: estandes de bancos (públicos e privados) na sede do Sindicalçados para captação de recursos e financiamento (médio e longo prazo).

- Capacitação de mão-de-obra: treinamento de testes de conforto e desenvolvimento de novos modelos/design, no laboratório do SENAI/ INMETRO.

- Divulgação dos Projetos: avaliação, monitoramento e divulgação na mídia dos projetos e ações que estão sendo realizados no APL de Jaú.

- Sistema de melhoria de qualidade para fornecedores, políticas de incentivos para o setor, projeto vendedor, projeto vitrine virtual dos produtos do APL, projeto extensionista e projeto de moda/ design.

Observou-se na revisão da literatura que em algumas regiões da Itália (distritos industriais italianos), os produtores têm apoio governamental. As "ações conjuntas" são realizadas entre produtores, governos e instituições privadas como infra-estrutura, presença de bancos locais (cooperativas de garantias de crédito), associações empresariais, sindicatos, universidades, centros de pesquisa, compra de matérias-primas em conjunto (consórcios), instituições religiosas, partidos políticos dentre outros. A cooperação entre os diversos atores dos distritos industriais italianos gera vantagens competitivas para os produtores e para a comunidade local. 
Verificou-se que as ações conjuntas, os programas e projetos que estão sendo realizados no APL de calçados femininos de Jaú geram ganhos coletivos aos produtores locais, bem como para as empresas da região.

Do ponto de vista regional, o caso das indústrias de calçados femininos de Jaú pode ser entendido como um processo interno de ampliação contínua de agregação de valor na produção, bem como da capacidade de absorção da região. Segundo Boisier (2000), o desenvolvimento de uma região depende de um conjunto de elementos políticos, institucionais e sociais que podem ser agrupados genericamente sob o título amplo de capacidade de organização social da região.

No que se refere às "ações conjuntas deliberadas entre os agentes locais" do APL de Jaú, existe um elevado escopo para melhor aproveitamento desse potencial, o que incrementaria ainda mais a capacidade competitiva dos produtores. A despeito desse espaço para o reforço de "ganhos coletivos" gerados a partir da aglomeração, percebeu-se que a competitividade dos produtores calçados de Jaú está fortemente associada aos benefícios que são gerados pela concentração dos produtores.

Verificou-se que no APL de calçados femininos de Jaú existem várias ações conjuntas entre os diversos atores do APL e tais "ações geram ganhos coletivos" para os produtores, para o local, para as pessoas que ali vivem, além de proporcionar ganhos para a região que se apropria dos benefícios advindos das ações conjuntas.

\section{Análise dos Resultados da Pesquisa Empírica}


A seguir apresenta-se os resultados da pesquisa empírica realizada no APL de calçados femininos de Jaú em relação ao objetivo principal da pesquisa, os objetivos específicos, a principal hipótese da pesquisa e as hipóteses secundárias da pesquisa.

O objetivo principal desta pesquisa foi "verificar a existência de ações conjuntas e ganhos coletivos no APL de calçados femininos de Jaú”. Pode-se observar através da pesquisa empírica a existência de grande quantidade de "ações conjuntas" entre os diversos atores de instituições públicas e privadas, os quais investiram um valor razoável (aproximadamente 9 milhões de reais) nos projetos.

Segundo Suzigan (2001), as economias externas ativas são decorrentes de "ações conjuntas deliberadas" das empresas com diversas instituições públicas e privadas. Verificou-se que da soma das "ações conjuntas" (economias externas ativas) entre as instituições do APL (ações e projetos) resulta a eficiência coletiva, que determina a vantagem competitiva das empresas locais. Segundo Porter (1999) as vantagens competitivas do arranjo produtivo local (APL) estão situadas do lado de "fora" da empresa e são geradas e sustentadas através de um processo altamente localizado. As vantagens competitivas são decorrentes das economias externas. Além de proporcionar custos reduzidos para as empresas há troca de informações entre os produtores, qualificação da mão-de-obra, melhorias para o meio ambiente, dentre outros.

Outro item que deve ser destacado é que as "ações conjuntas" entre os diversos atores do APL geram ganhos coletivos através das relações com os elos horizontais e verticais da cadeia produtiva como: participação governamental (municipal, estadual e nacional), pesquisa de universidades (pública e privada), instituições de pesquisa, centros tecnológicos e de pesquisa, políticas educacionais, incentivos fiscais aos produtores, presença de bancos financiadores (privados e públicos), inovação tecnológica local e regional, ações voltadas para 
o meio ambiente, aumento de renda local, geração de empregos, cooperação entre os produtores, exportação em conjunto, presença de sindicatos e associações de classe para desenvolvimento de ações do APL, dentre outras (PORTER, 1999).

\section{Relação de Cooperação entre os Diversos Atores do APL}

O primeiro objetivo específico é que as prioridades das relações de cooperação da empresa com os demais atores internos ${ }^{7}$ do APL são: i) relação com fornecedores de matéria-prima; ii) relação com centros tecnológicos; iii) relações com sindicatos e associações; iv) relações com universidades e faculdades; v) relações fornecedores de equipamentos; vi) relação com concorrentes (outras empresas); vi) relações com clientes; vii) relação com órgãos públicos.

A cooperação verificada nos distritos industriais italianos segundo Putnam (1996) aponta para a existência de capital social, a atuação coletiva vai sendo construída ao longo da história, baseados em confiança e respeito às regras e aos valores da localidade. Ramos (2001, p. 36) comenta a partir do texto de Putnam (1996):

O capital social é um "recurso moral" cuja oferta aumenta com o uso, e não o contrário, como ocorre no caso dos bens convencionais. Por outro lado, um recurso moral acaba por esgotar-se caso não seja utilizado com freqüência. Nesse sentido, ações coletivas esporádicas e em situações particulares não são suficientes para a criação do capital social.

A articulação e a cooperação entre as diversas ações entre as instituições de pesquisa provocam mudanças internas nas empresas em relação à qualificação da mão-de-obra,

\footnotetext{
7 Atores internos do APL: empresas fornecedoras de insumos e matérias-primas; empresas prestadoras de serviços; Sindicato trabalhista e patronal; associações comerciais; instituições de ensino e pesquisa (públicas e particulares); escolas técnicas (SENAI e SENAC), instituições de fomento (SEBRAE); instituições financeiras (bancos); e o Estado nos três níveis de governo (municipal, estadual e federal).
}

RBPPD/BRJPD| Vol. 2 | n. 3 |p. 294-333, 2020. 
qualidade dos calçados, designer, novos modelos e conforto. As instituições de pesquisa quando articuladas com os diversos atores do APL geram vantagem competitiva ao local através da cooperação

Apesar da existência de relações de cooperação entre empresas e atores do arranjo, o APL de calçados femininos de Jaú está muito longe de tornar-se um "distrito industrial", como é o caso dos distritos industriais italianos.

\section{Facilidades de Ingresso das Indústrias no Programa do APL}

O segundo objetivo específico é que as principais facilidades para o ingresso das empresas no programa do APL estão relacionadas com: i) promoção de mudança organizacional; ii) introdução de inovações de processos; iii) introdução de inovações de produtos; iv) possibilidade de expansão das vendas para outros estados e países; v) promoção de melhorias nos equipamentos e processos produtivos; vi) promoção de aprendizado tecnológico; vii) possibilidade de realizar esforços junto a governos em favor de tratamento mais justos às empresas locais; viii) maior cooperação com empresas e instituições de pesquisa; ix) busca de estruturas de fomento à empresas (financiamento e incentivos); e x) realização de projetos voltados para o meio ambiente.

Observou-se que o investimento do governo salienta as externalidades positivas (retornos crescentes de escala), melhora o ambiente de negócios, são capazes de proporcionar retornos para as empresas, diminui os riscos para a economia local, gera renda para o local e melhora a qualidade de vida das pessoas. Verificou-se que os produtores participam das ações desenvolvidas pelo Sindicalçados por entenderem que os projetos beneficiam o 
desenvolvimento da empresa, bem como a troca constante de informações geram conhecimento e aprendizagem.

\section{Vantagens Associadas à Localização da Empresa na Região}

O terceiro objetivo específico é que as principais vantagens associadas à localização da empresa na região estão ligados diretamente ao: i) aumento da renda local e maior geração de empregos; ii) facilidade de treinamento da mão-de-obra e qualidade da mão-de-obra; iii) iv) presença de fornecedores especializados; v) proximidade com clientes/consumidores; vi) proximidade com os fornecedores de máquinas e equipamentos; vii) disponibilidade de mão-de-obra; viii) ações voltadas para o meio ambiente; ix) ações conjuntas com o setor público e entre os produtores; $\mathrm{x}$ ) troca de informações administrativas e tecnológicas entre os produtores; xi) proximidade com universidades e centros de pesquisa.

A literatura que vai ao encontro desse objetivo teve como base conceitual uma pesquisa empírica nas indústrias de calçados do Vale do Sinos (RGS) e em Franca (SP) realizada por Garcia (2001, p. 176-177), o autor afirma que nas duas experiências de aglomeração de empresas produtoras de calçados, as características importantes dos clusters de empresas pode ser verificada, principalmente no que se refere à presença de uma "estrutura produtiva completa" em termos da produção de calçados. Encontrou-se nos dois arranjos fornecedores de matéria-prima, solados, adesivos e selantes, componentes utilizados na fabricação de calçados; fabricantes de máquinas e equipamentos para calçados; fornecedores de serviços especializados às empresas (na área de comercialização do produto); organismos de apoio e prestação de serviços às empresas (organismos de classe, centros de tecnologia, centros de treinamento de mão-de-obra), dentre outros. 
Salienta-se que nem "todas" as indústrias fornecedoras de matéria-prima, máquinas e equipamentos fazem parte da cadeia produtiva do APL de Jaú. Muitas indústrias possuem escritórios de representações e depósitos de componentes na cidade o que facilita a compra, diminui o preço dos materiais, intensifica as relações de troca de informações entre os empresários e os fornecedores propiciando um processo de aprendizado coletivo.

\section{Análise das Hipóteses da Pesquisa Empírica}

A principal hipótese dessa pesquisa afirma que as "ações conjuntas entre os diversos atores do APL de indústrias de calçados femininos de Jaú geram ganhos coletivos".

Verificou-se que as ações conjuntas entre os produtores e diversos atores do APL de Jaú geram ganhos coletivos aos produtores e proporcionam vantagens competitivas para as empresas locais (desenvolvimento endógeno) e para a região (desenvolvimento exógeno). Machado (2003, p. 10) afirma que segundo Schmitz (1995, p. 533):

O agrupamento de empresas abre oportunidades para ganhos de eficiência que os produtores individuais raramente podem ter". Segundo a autora: "A simples concentração geográfica e setorial das empresas não é garantia de eficiência coletiva, mas é condição necessária para uma série de desenvolvimentos posteriores (...). A concentração das empresas proporciona aos produtores o desenvolvimento e a presença de diversos fatores como: redução de custos; forte divisão de trabalho e especialização; presença de fornecedores de matérias-primas (componentes e máquinas), de serviços tecnológicos, contábeis e financeiros; presença de sindicatos (patronal e empregado); universidades; consultorias em diversas áreas; e instituições públicas e privadas que acabam se envolvendo nas diversas ações conjuntas do arranjo. Quanto maior for o número de ações e atores que estiverem envolvidos no engajamento do desenvolvimento e aprimoramento do arranjo mais forte é a eficiência coletiva do arranjo produtivo.

Verificou-se diversas ações conjuntas presentes no APL de calçados femininos de Jaú. A soma das diversas ações conjuntas encontradas no arranjo resulta em eficiência coletiva e transformam-se em vantagem competitiva para as empresas (locais e regionais).

Observou-se que as ações conjuntas entre os diversos atores do APL de indústrias de calçados femininos de Jaú geram ganhos coletivos para a comunidade. 


\section{Fatores que Interferem na Qualificação da Mão-de-Obra}

A primeira hipótese secundária desta pesquisa é que "os fatores que mais interferem na qualificação da mão-de-obra das empresas do APL calçadista de Jaú são os treinamentos em nível técnico efetuados nas instituições de ensino" (Sindicalçados, Senai e Sebrae) e a capacitação realizada na própria empresa.

Essa hipótese foi confirmada pela pesquisa e apontou que os fatores que mais interferem na qualificação da mão-de-obra são: treinamentos efetuados nas instituições do APL de Jaú (Senai, Sindicalçados e Sebrae) e a capacitação realizada na própria empresa

Para Marshal (1982), a existência concentrada de mão-de-obra qualificada e treinamento específico reduz custos para as empresas locais. Essas empresas apropriam-se de processos de aprendizado que são exógenos à firma, porém endógenos ao conjunto local de produtores. No APL de Jaú existe grande quantidade de organismos especializados em treinamento e na qualificação da mão-de-obra, pelo fato da indústria de calçado ter base técnica relativamente simplificada as habilidades são transferidas quase que naturalmente, pois as capacitações dos funcionários são formadas no próprio local de trabalho e com custos reduzidos para as empresas. Isso significa que os trabalhadores "aprendem fazendo".

A literatura afirma que a concentração de empresas gera oferta de mão-de-obra qualificada, porém no caso de do APL de Jaú não há disponibilidade de mão-de-obra, pois as indústrias absorvem todo o contingente existente no local. Para tanto algumas iniciativas estão sendo realizadas em parceria com instituições de ensino para aumentar e qualificar a mão-de-obra.

RBPPD/BRJPD| Vol. 2 | n. 3 |p. 294-333, 2020. 


\section{Políticas que Contribuem para a Coletividade das Empresas}

A segunda hipótese secundária é que as "políticas governamentais que mais contribuem para a coletividade das empresas são aquelas vinculadas ao meio ambiente". Os resultados apontaram que as políticas que mais contribuíram em ordem de prioridades foram: i) os programas de capacitação profissional e treinamento técnico; ii) os programas de apoio à consultoria técnica; iii) melhorias na educação básica; iv) linhas de crédito; v) divulgação do APL; vi) maior estabilidade macroeconômica;vii) “ações voltadas para o meio ambiente'; viii) investimento em infra-estrutura; ix) incentivos fiscais; x) incentivos à exportação.

Os resultados revelaram que as políticas governamentais que contemplem a melhoria e preservação do "meio ambiente" não se encontram em primeiro lugar como se supunha. Assim pode-se inferir que a segunda hipótese apresentou fortes indícios de não ser confirmada pelos respondentes (empresários). Porém através da pesquisa de campo pode-se constatar que as "ações voltadas para o meio ambiente" envolvem um grande contingente de atores preocupados em buscar soluções para o meio ambiente e mudar a mentalidade dos empresários do APL através dos programas de Desenvolvimento Sustentável e Gestão de Resíduo.

Verificou-se que as ações relacionadas ao meio ambiente do APL de Jaú iniciaram-se através de uma fiscalização governamental, pela Cesteb (em 2001), órgão controlador do meio ambiente do Estado de São Paulo. A ação deliberada teve como objetivo controlar as condições de aterros sanitários dos municípios e classificar os resíduos gerados pelas indústrias de calçados que são chamadas de raspa de couro ou pó de lixadeira e que apresentam concentração de cromo, substância empregada no processo de curtimento. Esse processo resulta num material altamente poluente, classificado pela NBR 10004, Resíduo

RBPPD/BRJPD| Vol. 2 | n. 3 |p. 294-333, 2020. 
Classe I (perigoso). Até então, os resíduos das indústrias de calçados eram recolhidos pela prefeitura municipal em caminhões desapropriados e depositados com o lixo doméstico no aterro municipal e fora dos padrões exigidos pela Cesteb.

$\mathrm{Na}$ visita realizada aos curtumes da região (Bocaina/SP) a visualização que se tem da cidade é "surreal". Na entrada, no centro e fora da cidade se vê micro e pequenas empresas instaladas no fundo do quintal das casas, as raspas de couro (west-blue: couro cru) são retirados dos veículos e depositados diretamente no solo a céu aberto pelos produtores sem nenhuma proteção. Indaguei sobre a possibilidade de contaminação do solo, doenças advindas de contaminação de ratos, dentre outras. A resposta foi: "Estamos começando a tomar providências para reverter este quadro. Estamos fazendo parcerias com a prefeitura municipal da cidade, sindicato, empresários, Sindicalçados de Jaú, Sebrae e projetos com a UFScar através de financiamento com a FINEP para buscar soluções para o problema”.

Contador Júnior (2004), em sua pesquisa no APL de Jaú e nas indústrias de couro (curtumes) da região conclui que o grande desafio da sociedade moderna é assegurar a manutenção do crescimento econômico sem hipotecar o patrimônio ambiental que é um bem inalienável. Os impactos ambientais não podem mais ser analisados de maneira isolada dos contextos socioeconômicos, políticos e culturais, principalmente os impactos ambientais causados pelo grande volume de resíduos industriais gerados na região de Jaú. Os órgãos fiscalizadores constantemente efetuam advertências, aplicam multas e exigem mudanças de posturas dos empresários.

É importante ressaltar que através de "ações conjuntas" os problemas diretamente ligados ao "meio ambiente" poderão ser sanados, a presença da universidade (através de pesquisa), os financiamentos advindos do governo municipal, estadual e federal são fundamentais para solucionar os problemas, além do engajamento de toda a comunidade. A 
cooperação entre produtores, instituições, governos e diversos atores são imprescindíveis para garantir uma vida mais saudável para a população que ali vive, bem como desenvolver e criar vantagens competitivas para as indústrias instaladas na cidade.

Segundo Contador Júnior (2004, p. 155), o APL de Jaú configura-se em um espaço potencial para a disseminação de tecnologias para tratamento, reaproveitamento e reciclagem de resíduos.

\section{Estratégias Adotadas para Aumento da Eficiência e da Inovação}

A terceira hipótese secundária é que "as estratégias adotadas pelas empresas para o aumento da eficiência e da inovação apontam como principais fatores a promoção de mudanças organizacionais compartilhadas com outras empresas e fomentadas por instituições públicas e privadas”. Os resultados apontaram para: i) promoção de mudanças organizacionais; ii) arranjos cooperativos com empresas e instituições de pesquisa; iii) promoção de melhorias nos equipamentos e processos produtivos; iv) introdução de inovações de produtos e processos; v) mudanças nas áreas administrativas; vi) investimentos em treinamento; vii) investimentos na área de vendas; viii) investimentos em práticas voltadas para o meio ambiente; ix) abertura de lojas no shopping de calçados; e x) busca de outras formas de financiamento.

As inovações adotadas pelas indústrias do APL nos últimos anos foram decorrentes de informações obtidas através de: i) seminários, cursos e palestras; ii) participação em feiras comerciais e industriais do setor; iii) aquisição de novos equipamentos; iv) participação nas reuniões do APL para troca de informações com outras empresas; v) contratação de consultoria especializada (SEBRAE); vi) visita de fornecedores de máquinas, equipamentos e 
matéria-prima; vii) troca de informações em encontros informais (igreja, restaurantes, clubes, associações filantrópicas, etc); e viii) contatos/pesquisas com universidades e centros tecnológicos.

Essas inovações adotadas pelas indústrias mudaram o designer/modelo dos calçados, alteraram o lay-out da fábrica, mudaram as características técnicas do processo produtivo, introduziram novas matérias-prima; implantaram novos processos na produção e no meio ambiente (Just-in-time, CAD e ISO 9000) e criaram novos produtos.

A hipótese apresentou fortes indícios de ser confirmada e através da literatura constatou-se que as estratégias adotadas pelas empresas para o aumento da eficiência e da inovação quando compartilhadas com outros atores do APL e com o apoio de instituições públicas e privadas promovem mudanças organizacionais internas nas empresas.

Diversos autores afirmam que a inovação apresenta um caráter local, que as interações entre fornecedores de matérias-primas e equipamentos, clientes, instituições de pesquisa, indústrias correlatas e de apoio, concorrentes é imprescindível à inovação tecnológica e à produção de novos produtos e processos, pois viabiliza os fluxos de informação e de conhecimento científico e tecnológico no processo de inovação.

O SEBRAE quando contratado pelos empresários ${ }^{8}$ do APL, através de "consultorias" promovem mudanças organizacionais nas diversas áreas (administrativa, produção, finanças e marketing)

Para Gorayeb (2002), o apoio de consultorias especializadas, treinamento de mão-de-obra, laboratórios para testes, etc., pode melhorar a estrutura institucional e é um instrumento de política que age para incentivar o "espírito cooperativo" entre as empresas.

\footnotetext{
${ }^{8}$ Durante as visitas nas indústrias de calçados e nos curtumes da cidade de Jaú e Bocaina a preocupação dos empresários na busca de melhoria dos processos produtivos é intensa, mesmo se tratando de empresas com pouca tecnológica. A melhoria no processo diminui custos, tempo e melhora a qualidade. Observou-se consultorias do SEBRAE são bem vistas e estão sendo cada vez mais adotadas pelos empresários.
}

RBPPD/BRJPD| Vol. 2 | n. 3 |p. 294-333, 2020. 
Instituições que oferecem serviços comuns podem criar um espaço físico para a convivência dos empresários, o que favorece a troca de informações e a construção da "atmosfera industrial”.

\section{Fatores que Dificultam o Ingresso das Empresas no Sindicalçados/Jaú}

A quarta e última hipótese secundária é que “o principal fator que dificulta o ingresso das empresas nas ações desenvolvidas pelo Sindicalçados está vinculado às dificuldades de relacionamento com outras empresas concorrentes do APL". Os resultados apontaram para: i) dificuldade de maior aproximação com empresas concorrentes; ii) dificuldades na realização de acordos cooperativos com empresas concorrentes; iii) ausência de interesse comum de negócios entre os empresários; iv) desarmonia entre as políticas macroeconômicas da região; v) dificuldade de acesso às informações sobre as ações desenvolvidas no sindicato; vi) dimensão limitada do mercado interno.

A literatura sobre o APL apresentada por diversos autores enfocam que existe grande resistência entre as empresas em fazer alianças com empresas concorrentes, desta forma a hipótese apresentou fortes indícios de ser confirmada.

Para Gorayeb (2002. P.173-174), “a decisão final de cooperar (ou não) é estritamente privada. Não é possível garantir a cooperação entre os agentes por decreto. Mas, a literatura mostra que existem algumas ações capazes de incentivar as empresas para a realização de projetos em conjunto com outras empresas e com as instituições locais”.

Noronha e Turchi $(2005$, p.7) afirmam que a questão da cooperação e competição entre as empresas:

[...] deriva do entendimento de que pequenas empresas aglomeradas em um espaço podem ser competitivas e ter papel importante no desenvolvimento nacional. A razão

RBPPD/BRJPD| Vol. 2 | n. 3 |p. 294-333, 2020. 
que explica o sucesso de um APL seria a existência de diversas formas de cooperação entre as empresas ou de uma mistura adequada entre competição e cooperação. Assim o debate econômico voltou-se fortemente para as questões da cooperação e das relações entre as firmas e os fatores que permitem ou restringem a cooperação entre firmas concorrentes. A cooperação (ou confiança tomada como pré-condição da cooperação) seria a principal razão do sucesso de APL na visão de determinados autores.

Para Sengenberger; Pyke (1999: 129), “[...] a confiança não surge da noite para o dia: desenvolve-se e cresce na medida em que as pessoas aprendem através da experiência, que a troca social pode e deve render proveitos extensos”. Knorringa e Meyer-Stamer (1999) assinalam que a não cooperação pode estar relacionada ao receio dos empresários em trocar informações confidenciais, por fabricarem o mesmo produto.

Na visita de campo "algumas” fábricas de porte médio e grande do APL de calçados e $\mathrm{Jaú}^{9}$ não permitiram a visita na fábrica, pois temem que os seus modelos sejam copiados pelos concorrentes. Outro item destacado pelos autores é o que a consolidação de ações associativas coletivas leva tempo para serem consolidadas. No arranjo produtivo de calçados de Jaú das 250 indústrias de calçados formais, apenas 22 participam das ações conjuntas com Sindicalçados. Existe desconfiança dos empresários devido a tentativas fracassadas de algumas ações conjuntas.

Segundo Knorringa e Meyer-Stamer (1999), estes fatores estão relacionados à cultura e à história das localidades e podem gerar espírito de desconfiança quando ocorre fracasso nas tentativas de construir um ambiente favorável a ações coletivas.

\section{Considerações Finais}

\footnotetext{
${ }^{9}$ Algumas empresas de médio e grande porte não responderam o questionário. Algumas empresas não permitem a entrada de pessoas na fábrica, geralmente são empresas com marcas famosas no mercado.
}

RBPPD/BRJPD| Vol. 2 | n. 3 |p. 294-333, 2020. 
A literatura sobre os arranjos produtivos locais enfoca que pequenas e médias empresas aglomeradas possuem forte grau de especialização da produção e que o processo produtivo apresenta muita flexibilidade, tendo em vista que as empresas desenvolvem competências específicas do processo produtivo. A concentração das empresas em um mesmo espaço fortalece a especialização da mão-de-obra. Pode-se observar que no APL de calçados femininos de Jaú há elevado grau de especialização da mão-de-obra e que as empresas possuem flexibilidade no processo produtivo.

Os modelos/designer dos calçados femininos mudam constantemente, pois acompanham os lançamentos da moda/estação. Essa mudança rápida exige maior flexibilidade das empresas que precisam acompanhar a moda que é ditada principalmente pela Europa. Os materiais utilizados na fabricação dos calçados femininos, as cores e desenhos do couro; formatos de saltos; enfeites; estampas nos forros; dentre outros mudam constantemente. Muitas empresas precisam adaptar as máquinas para poder fabricar os seus modelos. Em entrevista um chefe de produção comentou: "Nós estávamos pregando o enfeite da sandália à mão (costurando a mão), aí um funcionário disse que ficou sabendo que a empresa X estava pregando na máquina, fui imediatamente até a fábrica e perguntei para o dono como ele estava fazendo para pregar o enfeite na máquina. Ele me mostrou a peça da máquina de costura e eu voltei para a minha empresa e peguei uma peça que eu tinha e fiz alguns reparos com uma lima e deu certo. Passamos a pregar o enfeite na máquina, o que reduziu bastante o tempo da tarefa". Observa-se que os "segredos pairam no ar", que a troca de informações auxilia a redução dos custos e o tempo de fabricação do calçado.

A partir do que foi lançado na Europa, os produtores desenvolvem os seus modelos ou “copiam" os modelos e apresentam nas feiras do setor. Somente após fechamento das vendas os produtores começam a comparar as matérias-primas e a produzir os calçados. 
Observou-se que a maioria das empresas não cria os modelos, elas compram os modelos de estilistas ou "copiam" o que foi lançado. Em entrevista na empresa Y um empresário comentou: “Eu não preciso de estilista tenho uma máquina fotográfica vou para a feira da Itália e fotografo as vitrines e depois com as fotos faço os meus modelos". As maioria das pequenas empresas não possuem o profissional estilista/modelista devido ao alto salário que é pago para este profissional, somente algumas indústrias de porte médio e grande possuem esse profissional. Geralmente são empresas que fabricam os calçados com "marcas próprias" e não permitem que "pessoas" visitem a fábrica para que os modelos não sejam copiados.

Outra característica encontrada no APL de Jaú é a "falta de marca" desses calçados, ou seja, "os sapatos de Jaú não são vendidos e sim comprados“, por grandes lojistas com marca própria. A maioria das pequenas e médias empresas fabrica seus modelos para grandes magazines e lojas de grife com a marca própria. O principal comprador de calçados de Jaú são os empresários “Armênios” de grandes lojas e têm influência no preço final dos calçados.

Segundo Suzigan et. al (2003) "os aglomerados são caracterizados por combinações de vários enfoques, não restringindo-se somente a economia”. O autor apresenta as seguintes categorias analíticas: i) históricas; ii) pequenos eventos; iii) instituições; iv) contextos sociais e culturais; e v) políticas públicas.

Verificou-se que no APL de calçados femininos de Jaú tais características podem ser reconhecidas como: i) Históricas: a grande quantidade de indústrias de calçados; o sucesso e a sobrevivência das indústrias; o reconhecimento de um APL calçadista de calçados femininos; a especialização dos produtores de calçados (pode-se dizer que a maioria dos produtores entrevistados sabem fazer calçados); ii) Pequenos Eventos: apesar da indústria calçadista apresentar baixo nível tecnológico observou-se que devido às mudanças constantes nos 
modelos, as indústrias estão sempre introduzindo novos acessórios/componentes nos calçados. Algumas inovações são trazidas pelos fornecedores de máquinas e equipamentos, indústria química (cola), indústrias de materiais (salto, forma, solado, dentre outras); iii) Instituições: existe presença de sindicato (Sindicalçados) e do Sebrae no APL de Jaú que pode ser considerado um exemplo de promoção de "ações conjuntas" entre os diversos atores como universidades e faculdades, incubadoras de empresas, sindicatos da região, associações e diversas instituições locais e regionais (privadas e públicas); iv) Contextos Sociais e Culturais: constitui a base de confiança e de liderança local observou-se que no APL de Jaú o Sindicalçados (parceria com o Sebrae) é considerado o principal agente de liderança local, pois promove ações conjuntas entre os produtores e os agentes privados e públicos.

O engajamento de ações conjuntas pode ser observado pela participação de um contingente de atores como: prefeitura, Fiesp, bancos públicos e privados, Sebrae, universidades, Fatec, Senai, faculdades, institutos de pesquisa (Finep e IPT), que em conjunto realizam projetos para desenvolver e criar vantagens competitivas ao local (desenvolvimento endógeno) e para a região (desenvolvimento exógeno). Os produtores locais e regionais se apropriam das economias externas ativas (deliberadas) advindas de ações conjuntas entre os diversos atores do APL. As ações conjuntas são fundamentais para o ganho coletivo. O setor público municipal do APL de Jaú participa e coopera nos programas do APL. A prefeitura local participa através de financiamentos e doação de um prédio onde funciona a incubadora de empresas. A prefeitura fez doação de um terreno para a construção de um aterro para os resíduos de couro e financia as ações ambientais. Além da participação municipal há instituições estaduais e federais envolvidas nos projetos do APL.

A literatura sobre APL ressalta que o processo de engajamento e participação das empresas é de longo prazo, os empresários precisam entender que as "ações conjuntas” geram 
ganhos para todos, porém perpassa a idéia entre muitos empresários que as ações não trazem vantagem para sua empresa. Há conflito de interesse individual entre os produtores, eles só fazem investimentos financeiros nos projetos se tiverem a certeza que as ações trarão ganhos para a sua empresa e que o dinheiro investido será retornado de alguma maneira.

Verificou-se uma grande resistência dos produtores em estabelecer práticas de interação e cooperação. Apesar de existir baixa cooperação entre os produtores observou-se que eles são capazes de aproveitar os ganhos coletivos advindos de ações conjuntas que são geradas nas estruturas produtivas localizadas entre as diversas instituições (públicas e privadas).

Conclui-se que as ações conjuntas deliberadas (economias externas ativas) entre os diversos atores do APL geram ganhos coletivos e promovem vantagem competitiva na cadeia produtiva do aglomerado. Nota-se que as vantagens competitivas em relação às economias ativas (ações conjuntas deliberadas entre atores do arranjo) podem ser verificadas no arranjo, principalmente pela grande quantidade de ações conjuntas que estão sendo realizadas por diversas instituições públicas e privadas. A circulação e a troca de informações ocorrem de forma natural e resulta em um processo de aprendizado de caráter social e coletivo, o que beneficia não somente as empresas, mas também a sociedade local/regional através do desenvolvimento sustentável, geração de renda e emprego.

\section{REFERÊNCIAS}

ALVES, M.C. (2006). Arranjos produtivos locais: o caso das Indústrias de calçados femininos de Jaú. Tese (Doutorado) - Universidade Metodista de Piracicaba.

AMARAL FILHO, J. (1996). Desenvolvimento regional endógeno em um ambiente federalista. In: PLANEJAMENTO e políticas públicas. Brasília: IPEA.

AMATO NETO, J. (2000). Redes de cooperação produtiva e clusters regionais: oportunidades para pequenas e médias empresas. São Paulo: Atlas; Fundação Vanzolini.

RBPPD/BRJPD| Vol. 2 | n. 3 |p. 294-333, 2020. 
CAMPOS, R.R. (2003). Ampliando espaços de aprendizagem: um foco para políticas de estímulos aos arranjos produtivos locais. Disponível em: $<$ http://www.ucdb.br/coloquio/arquivos/Renato.pdf $>$. Acesso em: 15 abr. 2011.

CASSIOLATO, J.E.; LASTRES, H.M.M. (2005). Mobilizando Conhecimentos para Desenvolver Arranjos e Sistemas Produtivos e Inovativos Locais de Micro e Pequenas Empresas no Brasil. Disponível em: < http://redesist.ie.ufrj.br/glossario.php $>$. Acesso em: 15 abr. 2011.

CASSIOLATO, J. E.; LASTRES, H. M. M. O foco em arranjos produtivos e inovativos locais de micro e pequenas empresas. In: LASTRES, H. M. M.; CASSIOLATO, J. E.; MACIEL, M. L. (Orgs). Pequena empresa: cooperação e desenvolvimento local. São Paulo: Relumé Dumará, jul. 2003. Cap. 1, pág. 21-34.

CERVO, A.L.; BERVIAN, P.A. (2002). Metodologia científica. 5.ed. São Paulo: Prentice Hall.

CONTADOR JR., O. (2004). Tecnologia e proteção ambiental nas indústrias do couro e calçados na região de Jaú - SP. Dissertação (Mestrado) - Universidade de Araraquara, Centro Universitário de Araraquara, Araraquara.

GARCIA, R.C. (2001). Vantagens competitivas de empresas em aglomerações industriais: um estudo aplicado à indústria brasileira de calçados e sua inserção nas cadeias produtivas globais. Tese (Doutorado) - Universidade Estadual de Campinas, 2001.

GORAYEB, D.S. (2002). Políticas para aglomerações setoriais de pequenas empresas: algumas reflexões. Campinas: IE/UNICAAMP.

KNORRINGA, P.; MEYER-STAMER, J. (1999). New dimensions in local enterprise cooperation and development: from clusters to industrial districts. In: SUZIGAN, W. (Org.). Clusters e sistemas locais de inovação: estudos de casos e avaliação da região de Campinas. Campinas: Papirus.

LAKATOS, E.M.; MARCONI, M.A. (1995). Metodologia científica. São Paulo: Atlas.

LASTRES, H.M.M.; CASSIOLATO, J.E. (2003). Novas políticas na era do conhecimento: o foco em arranjos produtivos e inovativos locais. Revista Parcerias Estratégicas, Brasília, v.17, p.5-29, set .

MARSHALL, A. (1982). Princípios de economia: tratado introdutório. São Paulo : Abril Cultural, 1982.

NORONHA, E.G.;TURCHI, L. (2005). Política industrial e ambiente institucional na análise de arranjo produtivo local. Brasília: IPEA. (Texto para Discussão, 1076). Disponível em:<www.ipea.gov/publicações/textoparadiscussão>. Acesso em: 2 mar. 2015. 
OLIVEIRA, A.M.R. (1999). Análise da estrutura produtiva do pólo calçadista do município de Jaú: suas implicações sócio-econômicas e espaciais. Dissertação (Mestrado) Universidade Estadual Paulista, Rio Claro, 1999.

PORTER, M. (1998). Competição: estratégias competitivas essenciais (on competition). Rio de Janeiro: Campus.

PUTNAN, R. (1996). Comunidade e democracia: a experiência da Itália moderna. Rio de Janeiro: FGV.

SCHMITZ, H.; NADVI, K. (1999). Clustering and industrialization: introduction. World Development, Oxford, v.27, n.9, p.1503-1514, Sept.

SENGENBERGER, W.; PYKE, F. (1999). Distritos industriais e recuperação econômica local: questões de pesquisa e de política. In: COCO, G.; URANI, A.; GALVÃO, A.P. (Coord.). Empresários e emprego nos novos territórios produtivos: o caso da terceira Itália. Rio de Janeiro: DP\&A. p.101-146.

SUZIGAN, W. et al. (2005). Localização, inovação e aglomeração: o papel das instituições de apoio às empresas no Estado de São Paulo. São Paulo em Perspectiva, v. 19, n. 2, p. 86-100, abr./jun. 2005.

SUZIGAN, W.; FURTADO, J.; GARCIA, R. E SAMPAIO, S. E. K. (2003). Sistemas locais de produção: mapeamento, tipologia e sugestões de políticas. Trabalho apresentado no XXXI Encontro Nacional de Economia, da ANPEC - Associação Nacional de Centros de Pós-Graduação em Economia. Porto Seguro (BA), dezembro, e aceito para publicação na Revista de Economia Política.

SUZIGAN, W. (2001). Aglomerações industriais como focos de políticas. Revista de Economia Política, São Paulo, v.21, n.3.

VARGAS, M.A. (2003). Proximidade territorial, aprendizado e inovação: um estudo sobre a dimensão local dos processos de capacitação inovativa em arranjos e sistemas produtivos no Brasil. Tese (Doutorado) - Universidade Federal do Rio de Janeiro, Rio de Janeiro. 